\title{
Current status of laparoscopic repeat liver resection for hepatocellular carcinoma
}

\author{
Zenichi Morise \\ Department of Surgery, Fujita Health University School of Medicine Okazaki Medical Center, Okazaki AICHI 444-0827, Japan. \\ Correspondence to: Prof. Zenichi Morise, Department of Surgery, Fujita Health University School of Medicine Okazaki Medical \\ Center, Gotanda Harisakicho Okazaki, Okazaki AICHI 444-0827, Japan. E-mail: zmorise@fujita-hu.ac.jp
}

How to cite this article: Morise Z. Current status of laparoscopic repeat liver resection for hepatocellular carcinoma. Hepatoma Res 2020;6:79. http://dx.doi.org/10.20517/2394-5079.2020.76

Received: 4 Aug 2020 First Decision: 4 Sep 2020 Revised: 12 Sep 2020 Accepted: 21 Sep 2020 Published: 6 Nov 2020

Academic Editor: Ho-Seong Han Copy Editor: Cai-Hong Wang Production Editor: Jing Yu

\begin{abstract}
Although liver resection (LR) is often adopted to recurrent hepatocellular carcinomas, risks of complications and conversion reportedly increase in laparoscopic repeat $L R(L R L R)$. The indication is not agreed upon even with the recent advances of laparoscopic LR. We conducted an international propensity score matching study of LRLR and open repeat LR for hepatocellular carcinoma with 1,582 patients from 42 world centers. Propensity-score matched LRLR patients have smaller blood loss and longer operation time than open repeat LR patients. Median overall survival time was 8.94 years in open and 12.55 years in LRLR; although the difference was not significant, the $P$-value was 0.0855 and the better curve of LRLR is clearly separated from that of open. In our institution, we experienced 34 LRLR and 12 cases of three times or more repeat LR until 2019. There are no significant differences in operation time, blood loss, hospital stay, conversion, and morbidity rates among first, second, and third or higher laparoscopic LR, which is different from the open situation. However, postoperative bile leakage and intraoperative bleeding causing conversion did happen in the cases with repeat extended exposure of Glissonian pedicle. LRLR is feasible for selected patients. However, the procedure is under developing stage and further accumulation of experiences and evaluation are needed.
\end{abstract}

Keywords: Laparoscopic liver resection, hepatocellular carcinoma, re-do surgery

\section{INTRODUCTION}

Hepatocellular carcinoma (HCC) can occur in multifocal and metachronous style with the neoplastic background with chronic liver diseases. Repeat liver resection (LR) is often required for the condition ${ }^{[1,2]}$. 


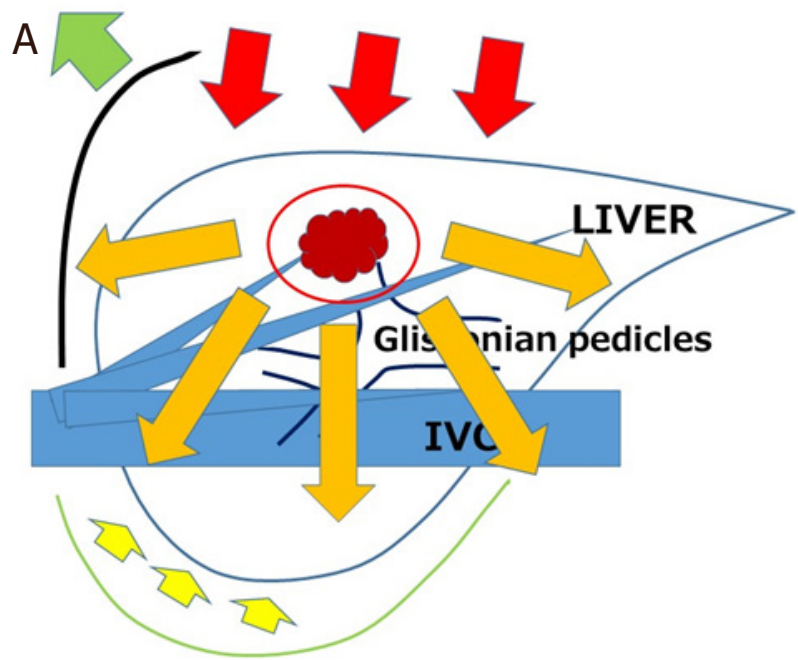

B

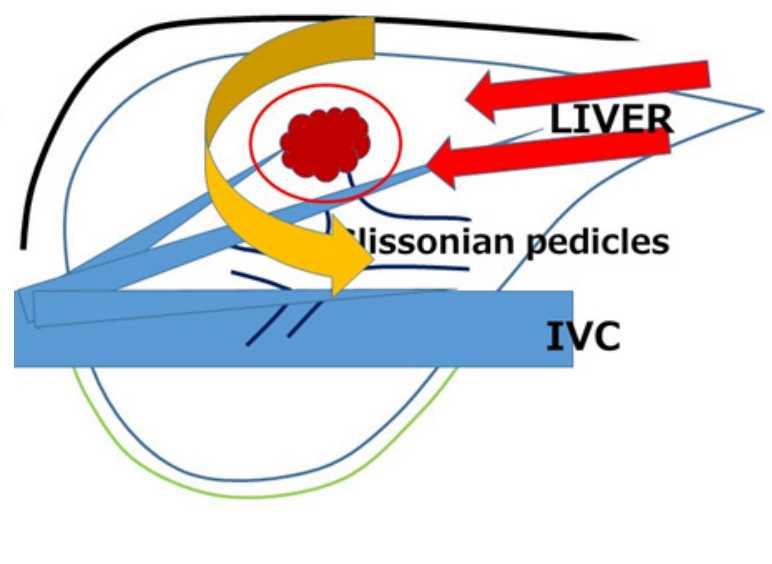

Figure 1. Open (A) and laparoscopic (B) repeat liver resections. The directions of view and manipulation in each approach are indicated with red arrows. A: in the open approach, the subphrenic rib cage is opened with a large subcostal incision and the liver is mobilized (lifted) from the retroperitoneum; B: in laparoscopic approach, the instruments intrude into the cage from the caudal direction, and the surgery is performed with minimal damage on the associated structures. Orange arrows indicate the dissection of adhesion. A: total adhesiolysis is performed in open procedure; B: direct approach to the tumor in laparoscopic procedure can facilitate small surface repeat liver resection with minimal adhesiolysis. IVC: inferior vena cav

After the beginning of laparoscopic LR (LLR) in the early $1990 \mathrm{~s}^{[3]}$, the accumulated experiences plus technical/technological advancements have expanded the indication of $\operatorname{LLR}^{[3-6]}$. However, the bulky and weighty liver protected inside the subphrenic "rib cage", and the invisible tumors/vessels inside it, should be handled in LR. There are obstacles to overcome in LLR: restricted manipulation, poor tactile sensation, and disorientation occurring under the limited laparoscopic view ${ }^{[7,8]}$. Increases in operation time and bowel injury were known in surgery with adhesion ${ }^{[9,10]}$, and increased morbidity and conversion in laparoscopic re-do surgeries have been reported ${ }^{[10,11]}$. Many laparoscopic re-do surgeries ${ }^{[10-14]}$ have become usual procedures; however, the application of laparoscopic repeat LR (LRLR) is controversial. Adhesion can disturb the liver mobilization and the dissections of vessels and Glissonian pedicles. Scars/adhesions causing the deformity of the liver and its internal structures disrupt the identifications of tumors and vessels. They increase the risks of complications and conversions during LRLR.

On the other hand, LLR is reported to have benefits, such as reductions of postoperative ascites and liver failure ${ }^{[15]}$, for patients with liver cirrhosis (LC) ${ }^{[16-18]}$. During open LR, the subphrenic "rib cage" in which the liver is protected is opened with subcostal incision, and the liver is mobilized for picking up. In LLR, directly intruding instruments to the cage perform the manipulation [Figure 1, "Caudal approach" ${ }^{[19-21]}$ ] with minimum damages to surrounding structures and collateral vessels in LC patients. Similarly, direct access with minimal adhesiolysis to the working space can be enabled, especially in small surface LRLR [Figure 1] ${ }^{[22-24]}$. It could be an advantage of LRLR over open repeat $\operatorname{LR}^{[24-27]}$.

This review describes the current status of LRLR for HCC from the result of our multi-institutional study and our own experiences.

\section{THE PROPENSITY SCORE MATCHING STUDY FOR HCC PATIENTS}

We conducted the first international propensity score matching study comparing LRLR to open repeat LR for HCC patients ${ }^{[28]}$ with 1,582 registered cases from 42 centers. LRLR was feasible for selected patients and not inferior to open procedure in both short- and long-term results of the study. The conversion rate of LLR patients in this study on an intention to treat basis was low (3.8\%), which might be caused by the 
patient selection. The fact that LRLR was currently adopted to patients of poor general and liver condition but with favorable factors related to tumors and surgical procedures was also shown. Notable differences between centers in the number and percentage of LRLRs were revealed. The number of LRLRs in each center ranged from 0 to 67 (median 10) and the rate among all cases was from $0 \%$ to 100\% (median $57.1 \%$ ). Furthermore, no correlation was found between the number and percentage $(P=0.349)$. It is thought to be because indications differ depending on each center's experience with different patient populations in terms of the prevalence of HCC, although all are high-volume centers of LR. LRLR for HCC is currently adopted only for patients with favorable characteristics depending on each center's experiences. It means that this procedure is still in its developing stage. All patients after matching, in comparison to those before matching, had better general and liver conditions, as well as tumors and surgery-related conditions. The patients after matching were favorable patients who would have been eligible for either LRLR or open repeat LR depending on the experience of each center.

The survival curve of LRLR patients after matching was clearly separated and better than that of open patients, although without significant difference (median 12.55 years $v s .8 .94$ years; $P=0.086$ ). On the other hand, disease-free survival after matching and overall survival before matching in laparoscopic and open repeat LRs were similar. Although LRLR patients before matching were selected with poorer liver function, matched LRLR patients had better liver function and might have been able to undergo repeated treatments due to less adhesion and liver function deterioration caused by laparoscopic approach. Although resection margin should be one of the important factors for long-term results of LR theoretically, the optimal resection margin for HCC remains controversial ${ }^{[29]}$. In our study, $6.25 \%$ of the data for resection margin could not be retrieved, and unfortunately this factor was not in the propensity-score matching analysis. However, among the patients with sufficient data, the rates of $\mathrm{R} 1$ resection in the original groups of open and laparoscopic repeat LR were $16.1 \%$ and $6.3 \%$. The rate in open group is comparable to and that in LRLR is lower than previous reports ${ }^{[29,30]}$. It is speculated that the status of resection margin in LRLR is not, at least, inferior to that in open, although this difference in our study may partially be caused by the fact that LRLR is currently adopted to patients of favorable factors related to tumors and surgical procedures.

For the short-term results, the study showed that LRLR was accompanied by less blood loss and a longer operation time. Decreased morbidity is considered as one of the advantages of LLR for HCC patients ${ }^{[22-25]}$. However, our matched patients have favorable liver function, and, thus, the impact of LLR might be lower. The differences in hospital stay between centers/areas, possibly due to insurance systems and hospitalization practices, were large and, thus, no difference should have been observed in hospital stay.

Currently, there is no randomized-control trial for open and laparoscopic repeat resection and only four propensity-score matching studies [Table 1] ${ }^{[31-33]}$. Besides our study, the studies include patients with other diseases than HCC with few data for long-term results. However, adding of only a few existing metaanalyses ${ }^{[34,35]}$, they all mentioned that LRLR for selected patients is feasible with, at least, comparable results to open procedure.

\section{OUR OWN EXPERIENCES}

Until 2019, we experienced 34 LRLR and 12 cases of three or more (up to five) times repeat LR [Table 2]. There are no cases with combined resection of another organ or LLR for two or more segments in repeat cases. In the comparison excluding first LLR cases with same features as well, there are no significant differences in operation time, blood loss, hospital stay, conversion, and morbidity rates among first, repeat, and three or more times repeat LLRs. This is different from the situation of open repeat LR. Open repeat LR takes generally more operation time and blood loss. This may be caused from that laparoscopic direct access to working space, after minimal adhesiolysis, can be enabled especially in small surface LRLR [Figure 1] ${ }^{[22-24]}$. We think it could be an advantage of LRLR over open repeat $\operatorname{LR}^{[24-27]}$. However, conversion rate and 
Table 1. Summary of previous reports of LRLR (propensity score matching analyses)

\begin{tabular}{|c|c|c|c|c|c|c|c|}
\hline Author & Year & Journal & $\begin{array}{c}\text { Study } \\
\text { design }\end{array}$ & Disease & $\begin{array}{c}\text { Number } \\
\text { (ORLR: LRLR) }\end{array}$ & Short-term outcomes & Long-term outcoms \\
\hline Morise et al. ${ }^{[28]}$ & 2020 & Br J Surg & $\begin{array}{l}\text { Multicenter } \\
\text { PSM }\end{array}$ & $\mathrm{HCC}$ & $934: 648$ & $\begin{array}{l}\text { Blood loss: LRLR favor } \\
\text { operation time: ORLR } \\
\text { favor }\end{array}$ & $\begin{array}{l}\text { OS no significant difference } \\
\text { DFS no significant } \\
\text { difference }\end{array}$ \\
\hline Inoue et al. ${ }^{[31]}$ & 2019 & $\begin{array}{l}\text { J Gastrointest } \\
\text { Surg }\end{array}$ & $\begin{array}{l}\text { Single } \\
\text { center PSM }\end{array}$ & $\begin{array}{l}\text { HCC, CRLM, } \\
\text { others }\end{array}$ & $97: 45$ & $\begin{array}{l}\text { Blood loss, hospital stay, } \\
\text { morbidity: LRLR favor }\end{array}$ & OS and DFS: not available \\
\hline van der Poel et al. ${ }^{[32]}$ & 2019 & Br J Surg & $\begin{array}{l}\text { Multicenter } \\
\text { PSM }\end{array}$ & CRLM & $154: 271$ & $\begin{array}{l}\text { Blood loss, operation } \\
\text { time, hospital stay: LRLR } \\
\text { favor }\end{array}$ & OS and DFS: not available \\
\hline Hallet et al. ${ }^{[33]}$ & 2017 & World J Surg & $\begin{array}{l}\text { Multicenter } \\
\text { PSM }\end{array}$ & CRLM & $349: 27$ & $\begin{array}{l}\text { Comparable (operation } \\
\text { time, BT, morbidity) }\end{array}$ & $\begin{array}{l}\text { OS: not available } \\
\text { DFS: comparable }\end{array}$ \\
\hline
\end{tabular}

LRLR: Iaparoscopic repeat liver resection; ORLR: open repeat liver resection; PSM: propensity score matching analysis; HCC: hepatocellular carcinoma; OS: overall survival; DFS: disease free survival; CRLM: colorectal carcinoma liver metastasis; BT: blood transfusion rate

Table 2. Short-term outcomes of first, repeat, and three or more times repeat laparoscopic liver resection

\begin{tabular}{lllcc}
\hline & 1st LLR $\boldsymbol{n}=\mathbf{8 4}$ & Repeat LLR $\boldsymbol{n}=\mathbf{3 4}$ & $\mathbf{3}$ or more times repeat $\boldsymbol{n}=\mathbf{1 2}$ & $\mathrm{NS}$ \\
\hline Operation time (min), mean \pm SD (median) & $293 \pm 128(262)$ & $292 \pm 136(256)$ & $299 \pm 146(274)$ & $\mathrm{NS}$ \\
Blood loss (mL), mean \pm SD (median) & $244 \pm 517(70)$ & $331 \pm 652(50)$ & $504 \pm 864(50)$ & $\mathrm{NS}$ \\
Length of hospital stay (day), mean \pm SD (median) & $20 \pm 30(15)$ & $18 \pm 2(12)$ & $26 \pm 33(14)$ & $\mathrm{NS}$ \\
Conversion & $2 / 84$ & $1 / 34$ & $1 / 12$ & $\mathrm{NS}$ \\
Morbidity (Grade III or higher) & $5 / 84$ & $2 / 34$ & $1 / 12$ & \\
\hline
\end{tabular}

Until 2019, we experienced 34 LRLR and 12 cases of three or more (up to five) times repeat LR. There are no cases with combined resection of the other organ or LLR for two or more segments in repeat cases. In the comparison excluding those cases as well, there are no significant differences in operation time, blood loss, hospital stay, conversion, and morbidity rates among first, repeat, and three or more times repeat LLRs. LRLR: laparoscopic repeat liver resection; LLR: laparoscopic liver resection; SD: standard deviation; NS: means that there is no statistically significant difference between the values of first, repeat, and three or more times repeat LLR

morbidity are higher in repeat than first surgeries, although it is not significant. Bile leakage and bleeding did happen in the cases with repeat extended exposure of Glissonian pedicle. Limited surgical field for view and manipulation with adhesion/scars around the hilar plate can lead to complicated repeat extended exposure of Glissonian pedicle. It is different from most repeat small surface resections. Evaluations of such LRLRs should be required after more accumulation of experiences.

\section{CONCLUSION}

Our propensity score study showed that neither short- nor long-term outcomes of LRLR for HCC in its current developing stage are inferior to those of open repeat LR. Although a large-scale study conducted after further establishment of the procedure and accumulation of experience is needed, LRLR is feasible for selected patients. There could be advantages of LRLR over open (especially for small surface resection), such as decreased blood loss, and less deterioration of liver function. However, repeat extended exposure of Glissonian pedicle could currently be the cause of complications, such as bile leakage and bleeding.

\section{DECLARATIONS}

\section{Authors' contributions}

The author contributed solely to the article.

\section{Availability of data and materials}

Not applicable

\section{Financial support and sponsorship}

None. 


\section{Conflicts of interest}

The author declared that there are no conflicts of interest.

\section{Ethical approval and consent to participate}

Institutional Review Board approval was obtained from Fujita Health University (HM17-164). Data collections and analyses were performed in accordance with the Declaration of Helsinki.

\section{Consent for publication}

Not applicable.

\section{Copyright}

(c) The Author(s) 2020.

\section{REFERENCES}

1. Morise Z, Kawabe N, Tomishige H, et al. Recent advances in the surgical treatment of hepatocellular carcinoma. World J Gastroenterol 2014;20:14381-92.

2. Itamoto T, Nakahara H, Amano H, et al. Repeat hepatectomy for recurrent hepatocellular carcinoma. Surgery 2007;141:589-97.

3. Morise Z, Wakabayashi G. First quarter century of laparoscopic liver resection. World J Gastroenterol 2017;23:3581-8.

4. Nguyen KT, Gamblin TC, Geller DA. World review of laparoscopic liver resection-2,804 patients. Ann Surg 2009;250:831-41.

5. Buell JF, Thomas MT, Rudich S, et al. Experience with more than 500 minimally invasive hepatic procedures. Ann Surg 2008;248:47586.

6. Wakabayashi G, Cherqui D, Geller DA, et al. Recommendations for laparoscopic liver resection: a report from the second international consensus conference held in Morioka. Ann Surg 2015;261:619-29.

7. Buell JF, Thomas MJ, Doty TC, et al. An initial experience and evolution of laparoscopic hepatic resectional surgery. Surgery 2004;136:804-11.

8. Vibert E, Perniceni T, Levard H, et al. Laparoscopic liver resection. Br J Surg 2006;93:67-72.

9. Beck DE, Ferguson MA, Opelka FG, et al. Effect of previous surgery on abdominal opening time. Dis Colon Rectum 2000;43:1749-53.

10. Karayiannakis AJ, Polychronidis A, Perente S, Botaitis S, Simopoulos C. Laparoscopic cholecystectomy in patients with previous upper or lower abdominal surgery. Surg Endosc 2004;18:97-101.

11. Wiebke EA, Pruitt AL, Howard TJ, et al. Conversion of laparoscopic to open cholecystectomy. An analysis of risk factors. Surg Endosc 1996;10:742-5.

12. Wu JM, Lin HF, Chen KH, et al. Impact of previous abdominal surgery on laparoscopic appendectomy for acute appendicitis. Surg Endosc 2007;21:570-3.

13. Law WL, Lee YM, Chu KW. Previous abdominal operations do not affect the outcomes of laparoscopic colorectal surgery. Surg Endosc 2005;19:326-30.

14. Nunobe S, Hiki N, Fukunaga T, et al. Previous laparotomy is not a contraindication to laparoscopy-assisted gastrectomy for early gastric cancer. World J Surg 2008;32:1466-72.

15. Morise Z, Ciria R, Cherqui D, et al. Can we expand the indications for laparoscopic liver resection? A systematic review and metaanalysis of laparoscopic liver resection for patients with hepatocellular carcinoma and chronic liver disease. J Hepatobiliary Pancreat Sci $2015 ; 22: 342-52$.

16. Morise Z, Sugioka A, Kawabe N, et al. Pure laparoscopic hepatectomy for hepatocellular carcinoma patients with severe liver cirrhosis. Asian J Endosc Surg 2011;4:143-6.

17. Wakabayashi G. Systematic reviews from the 2nd International Consensus Conference on Laparoscopic Liver Resection. J Hepatobiliary Pancreat Sci 2015;22:325-6.

18. Takahara T, Wakabayashi G, Beppu T, et al. Long-term and perioperative outcomes of laparoscopic versus open liver resection for hepatocellular carcinoma with propensity score matching: a multi-institutional Japanese study. J Hepatobiliary Pancreat Sci 2015;22:7217.

19. Tomishige H, Morise Z, Kawabe N, et al. Caudal approach to pure laparoscopic posterior sectionectomy under the laparoscopy-specific view. World J Gastrointest Surg 2013;5:173-7.

20. Soubrane O, Schwarz L, Cauchy F, et al. A conceptual technique for laparoscopic right hepatectomybased on facts and oncologic principles: the caudal approach. Ann Surg 2015;261:1226-31.

21. Wakabayashi G, Cherqui D, Geller DA, et al. Laparoscopic hepatectomy is theoretically better than open hepatectomy: preparing for the 2nd International Consensus Conference on Laparoscopic Liver Resection. J Hepatobiliary Pancreat Sci 2014;21:723-31.

22. Shafaee Z, Kazaryan AM, Marvin MR, et al. Is laparoscopic repeat hepatectomy feasible? A tri-institutional analysis. J Am Coll Surg 2011;212:171-9.

23. Hu M, Zhao G, Xu D, Liu R. Laparoscopic repeat resection of recurrent hepatocellular carcinoma. World J Surg 2011;35:648-55.

24. Isetani M, Morise Z, Kawabe N, et al. Pure laparoscopic hepatectomy as repeat surgery and repeat hepatectomy. World J Gastroenterol 
2015;21:961-8.

25. Ahn KS, Han HS, Yoon YS, Cho JY, Kim JH. Laparoscopic liver resection in patients with a history of upper abdominal surgery. World J Surg 2011;35:1333-9.

26. Ome Y, Hashida K, Yokota M, et al. The feasibility and efficacy of pure laparoscopic repeat hepatectomy. Surg Endosc 2018;32:3474-9.

27. Wakabayashi T, Felli E, Memeo R, et al. Short-term outcomes of laparoscopic repeat liver resection after open liver resection: a systematic review. Surg Endosc 2019;33:2083-92.

28. Morise Z, Aldrighetti L, Belli G, et al; ILLS-Tokyo Collaborator group. Laparoscopic repeat liver resection for hepatocellular carcinoma: a multicenter propensity score-based study. Br J Surg 2020;107:889-95.

29. Kobayashi N, Aramaki O, Midorikawa Y, et al. Impact of marginal resection for hepatocellular carcinoma. Surg Today 2020; doi: 10.1007/s00595-020-02029-z.

30. Martínez-Cecilia D, Wicherts DA, Cipriani F, et al. Impact of resection margins for colorectal liver metastases in laparoscopic and open liver resection: a propensity score analysis. Surg Endosc 2020; doi: 10.1007/s00464-020-07452-4.

31. Inoue Y, Fujii K, Ishii M, et al. Laparoscopic repeat hepatic resection for the management of liver tumors. J Gastrointest Surg 2019;23:2314-21.

32. van der Poel MJ, Barkhatov L, Fuks D, et al. Multicentre propensity score-matched study of laparoscopic versus open repeat liver resection for colorectal liver metastases. Br J Surg 2019;106:783-9.

33. Hallet J, Sa Cunha A, Cherqui D, et al; French Colorectal Liver Metastases Working Group, Association Française de Chirurgie. Laparoscopic compared to open repeat hepatectomy for colorectal liver metastases: a multi-institutional propensity-matched analysis of short- and long-term outcomes. World J Surg 2017;41:3189-98.

34. Peng L, Zhou Z, Xiao W, et al. Systematic review and meta-analysis of laparoscopic versus open repeat hepatectomy for recurrent liver cancer. Surg Oncol 2019;28:19-30.

35. Peng Y, Liu F, Wei Y, Li B. Outcomes of laparoscopic repeat liver resection for recurrent liver cancer: a system review and meta-analysis. Medicine (Baltimore) 2019;98:e17533. 